\title{
COVID-19 pandemic and waiting times in outpatient specialist care in Germany: an empirical analysis
}

\author{
Jennifer Muschol and Christian Gissel ${ }^{*}$ (i)
}

\begin{abstract}
Background: International healthcare systems face the challenge that waiting times may create barriers to accessing medical care, and that those barriers are unequally distributed between different patient groups. The disruption of healthcare systems caused by the COVID-19 pandemic could exacerbate this already strained demand situation. Using the German healthcare system as an example, this study aims to analyze potential effects of the COVID-19 pandemic on waiting times for outpatient specialist care and to evaluate differences between individual patient groups based on their respective insurance status and the level of supply.

Methods: We conducted an experiment in which we requested appointments by telephone for different insurance statuses in regions with varying levels of supply from 908 outpatient specialist practices in Germany before and during the COVID-19 pandemic. Data from 589 collected appointments were analyzed using a linear mixed effect model.

Results: The data analysis revealed two main counteracting effects. First, the average waiting time has decreased for both patients with statutory (mandatory public health insurance) and private health insurance. Inequalities in access to healthcare, however, remained and were based on patients' insurance status and the regional level of supply. Second, the probability of not receiving an appointment at all significantly increased during the pandemic.

Conclusions: Patient uncertainty due to the fear of a potential COVID-19 infection may have freed up capacities in physicians' practices, resulting in a reduction of waiting times. At the same time, the exceptional situation caused by the pandemic may have led to uncertainty among physicians, who might thus have allocated appointments less frequently. To avoid worse health outcomes in the long term due to a lack of physician visits, policymakers and healthcare providers should focus more on regular care in the current COVID-19 pandemic.
\end{abstract}

Keywords: COVID-19, Corona, Waiting time, Outpatient, Specialist, Health service, Healthcare access, Inequalities

\section{Background}

Waiting times are serious challenges for international healthcare systems. Since they affect patients' access to medical care, international institutions such as the Organisation for Economic Co-operation and Development (OECD) are addressing this issue [1].

Waiting times can negatively affect perceived satisfaction on the demand side by delaying treatments for

\footnotetext{
* Correspondence: cg@phec.de
}

Department of Health Economics, Justus Liebig University, Giessen, Germany patients, thus extending their state of suffering and leading to uncertainty $[2,3]$. In addition to declining patient satisfaction, however, the potential risk that waiting times lead to inferior health outcomes is a cause for concern. Study results show an association between increased waiting times and poorer health outcomes for some conditions such as psychosis, increased hospitalizations for ambulatory care sensitive conditions, and higher mortality [4-6].

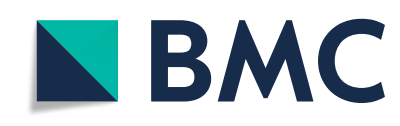

(c) The Author(s). 2021 Open Access This article is licensed under a Creative Commons Attribution 4.0 International License, which permits use, sharing, adaptation, distribution and reproduction in any medium or format, as long as you give appropriate credit to the original author(s) and the source, provide a link to the Creative Commons licence, and indicate if changes were made. The images or other third party material in this article are included in the article's Creative Commons licence, unless indicated otherwise in a credit line to the material. If material is not included in the article's Creative Commons licence and your intended use is not permitted by statutory regulation or exceeds the permitted use, you will need to obtain permission directly from the copyright holder. To view a copy of this licence, visit http://creativecommons.org/licenses/by/4.0/ The Creative Commons Public Domain Dedication waiver (http://creativecommons.org/publicdomain/zero/1.0/) applies to the data made available in this article, unless otherwise stated in a credit line to the data. 
Unequal access to care for specific groups is an additional challenge in many healthcare systems. International studies have analyzed this problem using various approaches. It has been shown that patient characteristics such as income, education and socioeconomic status can have a significant effect on the extent of waiting times and access to healthcare, resulting in inequalities. These effects are apparent in both inpatient [2, 7$10]$ and outpatient care $[11,12]$.

In addition to these factors, the insurance status of patients can also lead to unequal access to healthcare [13]. Although the distribution of waiting times is a significant component of everyday care for patients, empirical evaluations of the impact of insurance statuses on waiting times are limited in current research [14]. Few studies have so far addressed this issue in depth.

Germany, with its two-tier insurance system, provides a suitable framework for analyses of differences between insurance statuses $[15,16]$. Health insurance is mandatory in Germany and people are either covered by statutory health insurance (SHI) or by private health insurance (PHI). In 2021, around $89 \%$ of patients are covered by SHI, whereas $11 \%$ of the population are insured by PHI [17]. German SHI is a public scheme that is mandatory for the majority of the population. Only a minority of the population is exempt from SHI and can voluntarily take out PHI. SHI premiums are based on the income of the insured, whereas PHI premiums are risk-based [18]. Any unequal treatment of these two insurance groups may largely be due to the fact that physicians can charge medical interventions for PHI patients both more frequently and at higher rates [19]. The resulting financial incentive for physicians to treat PHI patients preferentially [15] has been evaluated in a small number of studies for both inpatient and outpatient settings in Germany. These studies show that PHI patients receive earlier access to care than SHI patients due to faster appointment scheduling $[14,15$, 19, 20]. Schwierz et al. also found that hospitals that discriminate based on patients' insurance status show better financial results [20].

Three studies analyzed experimental data of German outpatient specialist care: Lungen et al. (2008) [21], Heinrich et al. (2018) [22] and Werbeck et al. (2020) [23]. Using an experimental design in which outpatient specialists were called and asked for an appointment, these studies examined determinants of waiting times with a special focus on patients' insurance status. All three studies conclude that PHI patients receive preferential treatment regarding waiting times.

All of these observations show that difficulties arise both from waiting times themselves and from differences in waiting times between individual patient groups. As a result, international healthcare systems are trying to counter the effects resulting from a form of rationing
[10] and discrimination [11] through policy interventions [1], highlighting the fact that the organization of medical supply is critical.

The global COVID-19 outbreak, which was declared a pandemic by the World Health Organization (WHO) in March 2020 [24], could exacerbate this condition. COVID-19 is disrupting healthcare systems and medical care worldwide. This could have a major impact on previously existing structures and processes on the demand and supply side of healthcare [25]. Waiting times could be one of the variables that are strongly affected by the current pandemic.

Although research on COVID-19 is strong in a variety of fields, and there is heightened awareness of the need not to neglect patients without COVID-19 [26-28], there are currently no analyses of changes in waiting times in the context of the pandemic. This is what the present analysis focuses on. We seek to analyze the potential effect of the COVID-19 pandemic on outpatient specialist care in terms of waiting time and to evaluate differences for patient groups with different insurance statuses, using the German healthcare system as an example. In addition, our study contributes to the existing literature by explicitly including the level of supply in Germany and examining it for potential inequalities. It is evident that there are structural differences and barriers to accessing healthcare in Germany. According to the German Social Law, the goal of healthcare should be to ensure that patients are treated according to their needs and in a uniform manner. Favoring a particular patient group or accepting structural differences in care is inconsistent with this guiding principle $[19,29]$. In this sense, it is essential to consider the impact of the COVID-19 pandemic on an already strained demand situation.

\section{Methods \\ Data collection}

The present study was originally designed to analyze waiting times for outpatient specialist care for different patient groups based on their respective insurance status and the level of supply. However, due to the unexpected occurrence of the COVID-19 pandemic, the study objective was adapted. We therefore conducted an experiment in which we called outpatient specialist practices and asked for an appointment in order to evaluate waiting times and the impact of the COVID-19 pandemic. Data collection design is similar to that used by Lungen et al. [21], Heinrich et al. [22] and Werbeck et al. [23].

In line with the original study design, the analysis focused on general outpatient specialist care that was not directly involved in the treatment of COVID-19. Physicians of highly specialized medical fields were excluded. Surgeons and orthopedists, gynecologists, dermatologists, 
otorhinolaryngologists as well as ophthalmologists were contacted because they represented the most frequently practicing specialists.

Regionally, the federal state of Bavaria was examined, as the difference between over- and underserved areas was particularly pronounced there. Using data from the Bavarian Association of Statutory Health Insurance Physicians (BASHIP), the regions most affected by over- and undersupply were identified. With the help of the physician and psychotherapist search of BASHIP, the specialists of the medical specializations described above were selected in the respective regions. The first data collection took place in April 2019 and the second one in April 2020. In both years every practice was contacted by employees of the institute: once as a patient with $\mathrm{SHI}$ coverage and once as a patient with PHI coverage. The insurance status was randomized. The aim was to analyze potential differences in waiting times based on patients' insurance status.

On the basis of a given protocol, the practices were called and asked for the next possible appointment regardless of a specific physician. The reasons given for the examination were an eye examination, back pain, a gynecological examination, a hearing test and screening for skin cancer. These are, among others, the most common reasons for treatments by the respective specialists. All queries avoided giving the impression of an emergency. Each appointment was rejected at the end of the call to ensure that resources were protected. The time between the call and the first possible appointment was recorded. This number of days was adjusted for weekends and public holidays. Thus, the waiting time considered represents the number of weekdays. If no appointment was assigned, it was noted with a reason. Missing data for practices that were newly opened or closed in 2020 were also noted. Due to the repeated measurements and partially missing data, the observation represents an unbalanced panel.

\section{Statistical methods}

In a first step, results are presented as mean, standard deviation and median. Univariate statistics are considered to measure the influence of the COVID-19 pandemic on waiting times. The measurements (longitudinal data) are correlated because they were obtained from the same practices. Since waiting times are not normally distributed and observations are dependent, the non-parametric Wilcoxon signed-rank test was used to compare the parameters between 2019 and 2020. Pearson's Chi-squared test was applied to examine differences in the likelihood of receiving an appointment between insurance statuses. Because of multiple testing, the significance levels were adjusted by a Bonferroni-Holm correction.
Furthermore, in the context of the subsequent multivariate analysis, a linear mixed effect model (LMEM) was applied. LMEMs contain fixed effects that allow a systematic time trend component in the average response to be modelled to assess systematic differences between parameters with respect to the time trend. In addition, they take into account the correlation structure within practices and the random variation in time between practices on the basis of random effects.

Using the maximum-likelihood estimation procedure, a large number of differently constructed models were computed and compared based on the Akaike information criterion (AIC). The purpose was to find the best possible model for the data collected.

The computation of the intraclass correlation coefficient (ICC) with a random intercept only model revealed evidence of substantial clustering, where $42.4 \%$ of the variation in waiting times resulted from differences between practices. The variation in the random intercept was statistically significant. We included random intercepts for the practices as well as random slopes for the effect of year for the practices. Missing values were considered to be missing at random (MAR) because they do not depend on the waiting time itself.

Because of the non-normal distribution, the dependent variable waiting time was logarithmized. A simple and an extended model were used to analyze the data. The following equation reflects the simple model:

$\ln (W T)_{i j}=\left(\beta_{0}+u_{0 j}\right)+\left(ß_{1}+u_{1 j}\right)^{*}$ YEAR $_{i j}+\beta_{2}{ }^{*} \operatorname{SPEC}_{i j}+$

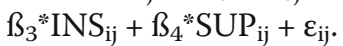

As fixed effects, we entered year, medical specialization, insurance status and level of supply.

Year is coded as a dummy variable for 2019 and 2020. The categorial variable medical specializations contains surgeons and orthopedists, gynecologists, dermatologists, otorhinolaryngologists and the reference group ophthalmologists. The remaining two fixed effects are also coded as dummies. PHI and SHI determine the insurance status, and the level of supply consists of oversupply and undersupply.

$\ln (W T)_{i j}=\left(\beta_{0}+u_{0 j}\right)+\left(\beta_{1}+u_{1 j}\right)^{*}$ YEAR $_{i j}+\beta_{2}{ }^{*} \operatorname{SPEC}_{\mathrm{ij}}+$

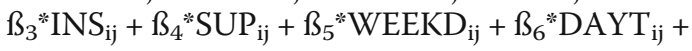
$\beta_{7}{ }^{*}\left(\mathrm{YEAR}_{\mathrm{ij}}{ }^{*} \mathrm{SPEC}_{\mathrm{ij}}\right)+\varepsilon_{\mathrm{ij}}$.

The extended model includes all effects of the simple model, despite a control for the fixed effects weekday of call categorized for the workdays Monday to Friday, with Friday as reference category and the dummy variable daytime of call comprising morning and afternoon. Additionally, an interaction effect between year and medical specialization was added. Visual inspection of residual plots for both models did not reveal any obvious deviations from linearity, homoscedasticity or normality. 


\section{Results}

There were $n=213$ practices in 2019 and $n=241$ practices in 2020 that were contacted twice. The number of practices changed because some practices were closed and others were reopened. Thus, a total of 908 observations were collected, which resulted in 598 appointments. The inclusion rate (percentage of appointments received from practices contacted) was $63.38 \%$ for SHI in 2019, $72.30 \%$ for PHI in 2019, 57.26\% for SHI in 2020 , and $67.22 \%$ for PHI in 2020, with an overall inclusion rate of $64.87 \%$.

The following reasons resulted in no appointment being set up. In $27.3 \%$ of the cases, the practice did not treat the inquired indication; $18.41 \%$ of practices were newly opened or closed within both years; $13.30 \%$ did not accept new patients; in $13.30 \%$ of cases the practices could not be reached by telephone; $13.30 \%$ of appointments were declined due to the COVID-19 pandemic; $11.25 \%$ of practices were on vacation or temporarily closed; finally, $3.07 \%$ of requests were denied because a referral was required or the practice could be visited without an appointment.

Table 1 shows the mean, standard deviation and median as well as the comparison of the parameters between 2019 and 2020 with help of the Wilcoxon signedrank test. There are strong deviations between the mean and the median within the groups as well as considerable differences in the mean waiting time between the individual groups.

The differences between the mean and median and the large standard deviation can be explained by strong outliers in the data set. For instance, the maximum waiting time is 162 days for SHI 2019, 120 days for PHI 2019, 259 days for SHI 2020, and 122 for PHI 2020. The graphical illustration of the waiting times showed that the data are not normally distributed; they are right skewed as well as leptokurtic.

The overview reveals that the longest mean waiting time, at 26.13 days, was faced by SHI patients in 2019 . PHI patients had to wait approximately nine days less, resulting in a mean of 17.37 days. For both insurance statuses, the waiting times decreased in 2020 by an overall average of almost 8 days or exactly $35.2 \%$ with 17.09 days for SHI patients and 11.09 days for PHI patients.

The Wilcoxon signed-rank test reveals significant differences in the comparison of the groups. The waiting time for SHI patients is significantly lower in 2020 than in $2019(\mathrm{z}=-4.33, p=<.001, n=102, \mathrm{r}=.43)$. The same applies for PHI patients $(\mathrm{z}=-4.01, p=<.001, n=124$, $\mathrm{r}=.36$ ). Simultaneously, the findings of the observation support the already existing literature [21-23]. Both in $2019(\mathrm{z}=-5.78, p=<.001, n=132, \mathrm{r}=.50)$ and in 2020 $(\mathrm{z}=-4.04, p=<.001, n=129, \mathrm{r}=.36)$ SHI patients had to face significantly longer waiting times than PHI patients. According to Cohen's effect size, 2019 shows a strong effect. However, it can also be seen that the overall difference in waiting time between SHI and PHI patients became significantly smaller in 2020 with a mean of 10.40 to 5.76 days $(\mathrm{z}=-2.20, p=.028, n=96, \mathrm{r}=.22)$. The change between the two years is also reflected in the level of supply. The average value between SHI and $\mathrm{PHI}$ patients was considered for under- and oversupplied

Table. 1 Test statistic - Wilcoxon signed-rank test

\begin{tabular}{|c|c|c|c|c|c|c|c|c|c|c|c|c|}
\hline Variables & $\mathrm{n}$ & Mean & SD & Median & Variables & $\mathrm{n}$ & Mean & SD & Median & $\mathbf{z}$ & $\mathbf{p}$ & $r$ \\
\hline Waiting time $19 \mathrm{SHI}$ & 135 & 26.13 & 29.55 & 15 & Waiting time $20 \mathrm{SHI}$ & 138 & 17.09 & 30.48 & 5 & -4.33 & $\begin{array}{l}< \\
.001\end{array}$ & .43 \\
\hline Waiting time $19 \mathrm{PHI}$ & 154 & 17.37 & 20.25 & 12 & Waiting time $20 \mathrm{PHI}$ & 162 & 11.09 & 18.83 & 4 & -4.01 & $\begin{array}{l}< \\
.001\end{array}$ & .36 \\
\hline Waiting time 19 SHI & 135 & 26.13 & 29.55 & 15 & Waiting time $19 \mathrm{PHI}$ & 154 & 17.37 & 20.25 & 12 & -5.78 & $\begin{array}{l}< \\
.001\end{array}$ & .50 \\
\hline Waiting time $20 \mathrm{SHI}$ & 138 & 17.09 & 30.48 & 5 & Waiting time $20 \mathrm{PHI}$ & 162 & 11.09 & 18.83 & 4 & -4.04 & $\begin{array}{l}< \\
.001\end{array}$ & .36 \\
\hline Difference 19 & 132 & 10.40 & 23.75 & 2 & Difference 20 & 129 & 5.76 & 22.14 & 1 & -2.20 & .028 & .22 \\
\hline Waiting time undersupply 19 & 43 & 24.78 & 21.31 & 17 & Waiting time undersupply 20 & 41 & 18.57 & 29.55 & 6.5 & -2.94 & .003 & .54 \\
\hline Waiting time oversupply 19 & 89 & 18.52 & 21.67 & 10.5 & Waiting time oversupply 20 & 88 & 8.93 & 10.33 & 4 & -3.75 & $\begin{array}{l}< \\
.001\end{array}$ & .46 \\
\hline $\begin{array}{l}\text { Waiting time Surgeons \& } \\
\text { Orthopedists } 19\end{array}$ & 38 & 10.79 & 9.30 & 7 & $\begin{array}{l}\text { Waiting time Surgeons } \\
\& \text { Orthopedists } 20\end{array}$ & 40 & 4.34 & 4.98 & 3 & -4.71 & $\begin{array}{l}< \\
.001\end{array}$ & .86 \\
\hline Waiting time Gynecologists 19 & 39 & 23.59 & 28.53 & 15 & Waiting time Gynecologists 20 & 38 & 20.30 & 18.34 & 15.25 & -.97 & .330 & .19 \\
\hline Waiting time Dermatologists 19 & 14 & 34.40 & 17.45 & 31 & Waiting time Dermatologists 20 & 8 & 12.75 & 9.27 & 12.25 & -2.02 & .043 & .90 \\
\hline $\begin{array}{l}\text { Waiting time } \\
\text { Otorhinolaryngologists } 19\end{array}$ & 23 & 18.63 & 20.35 & 9 & $\begin{array}{l}\text { Waiting time } \\
\text { Otorhinolaryngologists } 20\end{array}$ & 26 & 3.88 & 2.85 & 3.25 & -3.96 & $\begin{array}{l}< \\
.001\end{array}$ & .87 \\
\hline Waiting time Ophthalmologists 19 & 18 & 26.31 & 20.30 & 21.75 & $\begin{array}{l}\text { Waiting time Ophthalmologists } \\
20\end{array}$ & 17 & 23.50 & 38.45 & 12.5 & -1.78 & .075 & .49 \\
\hline
\end{tabular}


regions. The waiting times decreased from 24.78 in 2019 to 18.57 days in $2020(\mathrm{z}=-2.94, p=.003, n=30, \mathrm{r}=.54)$ in regions with undersupply and from 18.52 to 8.93 days $(\mathrm{z}=-3.75, p=<.001, n=66, \mathrm{r}=.46)$ in regions with oversupply. In this context, it is noticeable that patients in underserved regions face higher waiting times than those in overserved regions. Considerable differences are also apparent when considering the medical specializations. The average waiting time for SHI and PHI patients decreased for all specializations. While the results for gynecologists and ophthalmologists are not statistically different from zero, the mean waiting times for surgeons and orthopedists decreased significantly by 6.45 days $(\mathrm{z}=-4.71, p=<.001, n=30, \mathrm{r}=.86)$, for dermatologists by 21.65 days $(\mathrm{z}=-2.02, p=.043, n=5, \mathrm{r}=.90)$ and for otorhinolaryngologists by 14.75 days $(\mathrm{z}=-3.96, p=$ $<.001, n=21, \mathrm{r}=.87)$ in 2020. This represents strong effects according to Cohen's d. Thus, it appears that waiting times decreased for all parameters due to the COVID-19 pandemic.

It should be noted, however, that the result for dermatologists and the difference between the insurance statuses 2019 and 2020 are no longer statistically different from zero after a Bonferroni-Holm correction.

In addition to considering the waiting times within the groups, the probability of receiving an appointment at all was also analyzed using Pearson's chi-square. To avoid bias, only two reasons that practices offered for not making assignments were considered here: not accepting new patients and not assigning appointments due to the COVID-19 pandemic. The results can be found in Table 2.

The analysis shows that the probability of receiving an appointment decreased significantly in 2020 (80.9\%) compared to $2019(89.8 \%)\left(\chi^{2}(1)=10.68, p=.001, n=\right.$
693, $\mathrm{V}=.124)$. The lower likelihood of receiving an appointment due to the COVID-19 pandemic is also reflected in the segmentation between the insurance statuses. SHI patients received significantly fewer appointments when comparing 2019 (84.4\%) to 2020 (74.6\%). $\left(\mathrm{X}^{2}(1)=4.97, p=.026, n=345, \mathrm{~V}=.120\right)$. Also, PHI patients received appointments less frequently between $2019(95.1 \%)$ and 2020 (87.1\%) $\left(\chi^{2}(1)=6.58, p=.010\right.$, $n=348, \mathrm{~V}=.137)$. At the same time, unequal access to healthcare is also evident in the likelihood of receiving an appointment. Thus, SHI patients (79.1\%) were significantly less likely to receive an appointment than PHI patients $(90.08 \%)$ in both years $\left(\mathrm{X}^{2}(1)=18.51, p<.001, n=\right.$ $693, \mathrm{~V}=.163)$. This is also reflected in the analysis of the two years. PHI patients were more likely to receive appointments both in 2019 (95.1\%) and in 2020 (87.1\%) than SHI patients (2019: 84.4\%, 2020: 74.6\%) (2019: $\left(\mathrm{X}^{2}(1)=10.00, p=.002, n=322, \mathrm{~V}=.176\right) ; 2020:\left(\mathrm{X}^{2}(1)=\right.$ 9.37, $\mathrm{p}=.002, n=371, \mathrm{~V}=.159))$.

The decreased likelihood of receiving an appointment in 2020 is also evident in underserved regions with $11.5 \%$ fewer appointments $\left(x^{2}(1)=5.10, p=.024, n=238\right.$, $\mathrm{V}=.146)$ and in overserved regions with $7.5 \%$ fewer appointments $\left(\chi^{2}(1)=5.64, p=.018, n=455, \mathrm{~V}=.111\right)$.

The probabilities decreased in all medical specializations, but the change was only significant for gynecologists, who went from $86.3 \%$ in 2019 to $73.6 \%$ in 2020 $\left(\chi^{2}(1)=5.50, p=.019, n=227, \mathrm{~V}=.156\right)$, and for dermatologists, who went from $96.8 \%$ to $69.4 \%\left(x^{2}(1)=8.46\right.$, $p=.004, n=67, \mathrm{~V}=.355)$. Again, the effects for SHI appointments 2019 compared to 2020, for undersupply and oversupply, and for gynecologists do not hold up to a Bonferroni-Holm correction.

Throughout this analysis, no expected cell frequencies were below five, except for surgeons and orthopedists on

Table.2 Test statistic - Pearson's chi-square

\begin{tabular}{|c|c|c|c|c|c|c|c|c|}
\hline Variables & Probability & Variables & Probability & $x^{2}$ & df & $p$ & $\mathrm{n}$ & v \\
\hline Appointment 19 & $89.8 \%$ & Appointment 20 & $80.9 \%$ & 10.68 & 1 & .001 & 693 & .124 \\
\hline Appointment SHI 19 & $84.4 \%$ & Appointment SHI 20 & $74.6 \%$ & 4.97 & 1 & .026 & 345 & .120 \\
\hline Appointment PHI 19 & $95.1 \%$ & Appointment PHI 20 & $87.1 \%$ & 6.58 & 1 & .010 & 348 & .137 \\
\hline Appointment SHI both years & $79.1 \%$ & Appointment PHI both years & $90.8 \%$ & 18.51 & 1 & $<.001$ & 693 & .163 \\
\hline Appointment SHI 19 & $84.4 \%$ & Appointment PHI 19 & $95.1 \%$ & 10.00 & 1 & .002 & 322 & .176 \\
\hline Appointment SHI 20 & $74.6 \%$ & Appointment PHI 20 & $87.1 \%$ & 9.37 & 1 & .002 & 371 & .159 \\
\hline Undersupply 19 & $87.3 \%$ & Undersupply 20 & $75.8 \%$ & 5.10 & 1 & .024 & 238 & .146 \\
\hline Oversupply 19 & $91.0 \%$ & Oversupply 20 & $83.5 \%$ & 5.64 & 1 & .018 & 455 & .111 \\
\hline Surgeons \& Orthopedists 19 & $96.3 \%$ & Surgeons \& Orthopedists 20 & $95.6 \%$ & .05 & 1 & .820 & 170 & .017 \\
\hline Gynecologists 19 & $86.3 \%$ & Gynecologists 20 & $73.6 \%$ & 5.50 & 1 & .019 & 227 & .156 \\
\hline Dermatologists 19 & $96.8 \%$ & Dermatologists 20 & $69.4 \%$ & 8.46 & 1 & .004 & 67 & .355 \\
\hline Otorhinolaryngologists 19 & $100 \%$ & Otorhinolaryngologists 20 & $98.2 \%$ & .86 & 1 & .353 & 102 & .092 \\
\hline Ophthalmologists 19 & $75.8 \%$ & Ophthalmologists 20 & $66.2 \%$ & 1.43 & 1 & .231 & 127 & .106 \\
\hline
\end{tabular}


the one hand and otorhinolaryngologists on the other. For these two comparisons, Fisher's exact test was applied, but without showing effects statistically different from zero.

The comparison of the overall effects for the simple and extended model can be seen in Table 3 .

The results of the LMEMs for both models are presented in Table 4. Compared to the simple model with an AIC of 1578, the extended model exhibits an AIC of 1551 and can thus display the data more appropriately. Nevertheless, the comparison of the simple with the extended model was applied to examine the robustness of the results. The comparison reveals that, despite controlling for weekday and time of call as well as including an interaction term in the extended model, the main effects are almost the same in both models. Thus, it can be assumed that both models can robustly represent the effects.

For the simple model, the overall effect of all independent variables on the logarithmized dependent variable waiting time are statistically significant at the 5\% significance level. However, when considering the different medical specializations, it is found that only the effects of surgeons and orthopedists as well as otorhinolaryngologists are statistically significant compared with the reference group of ophthalmologists. Compared with ophthalmologists, patients in surgeons' and orthopedists' practices have to face $70.03 \%$ (exact computation: $\left.100\left(\mathrm{e}^{(-1.205)}-1\right)\right)$ less waiting time $(p=$ $<.001, \mathrm{~b}=-1.205, \mathrm{SE}=.173)$. For otorhinolaryngologists, the waiting time is $62.47 \%$ less than for ophthalmologists $(p=<.001, \mathrm{~b}=-.980, \mathrm{SE}=.194)$. The comparison with gynecologists and dermatologists is not statistically different from zero. Considering the year, it appears that COVID-19 reduced waiting time by 7.97 days or $52.43 \%$ for patients in 2020 compared to $2019(p=<.001, \mathrm{~b}=$ $-.743, \mathrm{SE}=.078)$. The insurance status also plays an important role in this model, showing that PHI patients have a $35.27 \%$ reduction in waiting time (4.60 days) compared with SHI patients $(p=<.001, \mathrm{~b}=-.435 \mathrm{SE}=.063)$.
In addition, the simple model reveals that patients in overserved regions receive appointments $31.48 \%$ or 3.98 days faster than in underserved regions $(p=.001, \mathrm{~b}=$ $-.378, \mathrm{SE}=.116)$.

The directions of the effects all remain the same in the extended model and, moreover, all significant results persist. Again, the overall effects are significant at the 5\% level, regardless of the extension of the model.

The fixed effects insurance status and level of supply remain unchanged in the extended model. Hence, PHI patients also receive appointments significantly faster in this design. SHI patients have an increased waiting time by 4.73 days or $35.08 \%(p=<.001, \mathrm{~b}=-.432 \mathrm{SE}=.060)$. In addition, appointments are scheduled $30.72 \%$ faster in overserved than in underserved regions (4.01 days) ( $p=$ $.002, \mathrm{~b}=-.367, \mathrm{SE}=.116$ ).

The fixed effects weekday and daytime of call show overall significant effects. Considering the individual effects, however, it is evident that they are partly not statistically different from zero. Simultaneously, the other results of the model remain stable. This demonstrates that controlling for weekday and daytime does not reduce the influence of the other effects.

Nevertheless, the extension of the model reveals that the effect of year on waiting time is influenced by the different medical specializations. The cross-level interaction shows that the effect of year varies depending on the individual medical specializations. Although the general effect of the year remained nearly stable, with the inclusion of the interaction effect patients received appointments on average $55.60 \%$ or 9.05 days faster in 2020 compared to $2019(p=<.001, \mathrm{~b}=-.812, \mathrm{SE}=.079)$.

With regard to the medical specializations, the comparison between ophthalmologists and three different groups (i.e. surgeons and orthopedists, gynecologists, and otorhinolaryngologists) is statistically significant in this model. On average, patients receive appointments $66.11 \%$ faster for surgeons and orthopedists $(p=<.001$, $\mathrm{b}=-1.082, \mathrm{SE}=.190), 32.50 \%$ faster for gynecologists $(p=.034, \mathrm{~b}=-.393 \mathrm{SE}=.185)$, and $48.98 \%$ faster for

Table.3 LMEM - Comparison of the Overall Effects of the Models

\begin{tabular}{|c|c|c|c|c|c|c|c|c|}
\hline \multirow[b]{2}{*}{ Source } & \multicolumn{4}{|c|}{ Simple Model } & \multicolumn{4}{|c|}{ Extended Model } \\
\hline & $\mathrm{N} \mathrm{df}$ & D df & $\mathrm{F}$ & $\overline{p \text {-Value }}$ & $\mathrm{N} \mathrm{df}$ & D df & $\mathrm{F}$ & p-Value \\
\hline Intercept & 1 & 190.69 & 1383.61 & $<.001$ & 1 & 234.22 & 1224.95 & $<.001$ \\
\hline Medical specialization & 4 & 191.71 & 21.86 & $<.001$ & 4 & 186.62 & 23.89 & $<.001$ \\
\hline Year & 1 & 199.45 & 90.49 & $<.001$ & 1 & 169.79 & 105.12 & $<.001$ \\
\hline Insurance status & 1 & 175.54 & 48.41 & $<.001$ & 1 & 167.14 & 51.30 & $<.001$ \\
\hline Level of supply & 1 & 193.56 & 10.55 & .001 & 1 & 183.87 & 9.97 & .002 \\
\hline Weekday & & & & & 4 & 385.56 & 3.57 & .007 \\
\hline Daytime & & & & & 1 & 320.15 & 4.76 & .030 \\
\hline Medical specialization * Year & & & & & 4 & 166.44 & 9.24 & $<.001$ \\
\hline
\end{tabular}


Table.4 LMEM - Comparison of the Models

\begin{tabular}{|c|c|c|c|c|c|c|}
\hline \multirow[b]{2}{*}{ Parameters } & \multicolumn{2}{|c|}{ Simple Model } & \multirow[b]{2}{*}{ p-Value } & \multicolumn{2}{|c|}{ Extended Model } & \multirow[b]{2}{*}{ p-Value } \\
\hline & Estimate & SE & & Estimate & SE & \\
\hline Intercept & 3.597 & .166 & $<.001$ & 3.394 & .188 & $<.001$ \\
\hline Surgeons \& Orthopedists & -1.205 & .173 & $<.001$ & -1.082 & .190 & $<.001$ \\
\hline Gynecologists & -.217 & .167 & .195 & -.393 & .185 & .034 \\
\hline Dermatologists & .046 & .219 & .834 & .211 & .240 & .382 \\
\hline Otorhinolaryngologists & -.980 & .194 & $<.001$ & -.673 & .212 & .002 \\
\hline Year 2020 & -.743 & .078 & $<.001$ & -.750 & .180 & $<.001$ \\
\hline $\mathrm{PHI}$ & -.435 & .063 & $<.001$ & -.432 & .060 & $<.001$ \\
\hline Oversupply & -.378 & .116 & .001 & -.367 & .116 & .002 \\
\hline Friday & & & & -.140 & .132 & .290 \\
\hline Thursday & & & & .078 & .086 & .363 \\
\hline Wednesday & & & & .305 & .113 & .008 \\
\hline Tuesday & & & & .258 & .111 & .020 \\
\hline Afternoon & & & & .168 & .077 & .030 \\
\hline $\begin{array}{l}\text { Year } 2020^{*} \\
\text { Surgeons \& Orthopedists }\end{array}$ & & & & -.238 & .225 & .292 \\
\hline $\begin{array}{l}\text { Year } 2020^{*} \\
\text { Gynecologists }\end{array}$ & & & & .619 & .227 & .007 \\
\hline $\begin{array}{l}\text { Year } 2020^{*} \\
\text { Dermatologists }\end{array}$ & & & & -.105 & .301 & .728 \\
\hline $\begin{array}{l}\text { Year 2020* } \\
\text { Otorhinolaryngologist }\end{array}$ & & & & -.584 & .250 & .021 \\
\hline
\end{tabular}

otorhinolaryngologists $(p=.002, \quad \mathrm{~b}=-.673, \quad \mathrm{SE}=.212)$ compared with ophthalmologists. At the same time, the significant interaction effects for gynecologists and otorhinolaryngologists over time have to be considered. These indicate that waiting times developed differently for the individual specializations. The significant interaction effect for gynecologists shows that this specialization developed differently over time compared to ophthalmologists $(p=.007, \mathrm{~b}=.619, \mathrm{SE}=.227)$. On average, patients thus receive appointments at gynecologists more quickly than at ophthalmologists in both years. Yet, compared to ophthalmologists in 2020, the waiting time remains almost stable for gynecologists. The significant negative interaction effect for otorhinolaryngologists $(p=.021, \mathrm{~b}=-.584, \mathrm{SE}=.250)$ reveals that in 2020 the waiting times for otorhinolaryngologist appointments decreased more strongly than those for ophthalmologist appointments.

\section{Discussion}

The main purpose of this study was to examine whether the COVID-19 pandemic caused changes in waiting times for outpatient specialist care in Germany. The analysis of the experimental data revealed two major findings. First, in line with the results from the univariate analysis, the multivariate analysis was able to expose, among other effects, that waiting times decreased significantly between 2019 and 2020. Second, however, it was also found that the probability of receiving an appointment at all significantly decreased at the same time. These counteracting effects could be caused by both sides of the physician-patient relation.

On the one hand, it appears desirable that waiting times have decreased in 2020 compared to 2019. On the other hand, the question is what reasons led to this change. These reasons cannot be clearly determined by the analysis.

International studies show a reduction in medical conditions unrelated to COVID-19 in hospitals and emergency departments (ED), for example (acute) myocardial infarction or strokes [30-32]. This can be explained by the fact that overall hospital and ED visits decreased, especially early in the pandemic, leading to an increase in mortality as urgent cases could not be treated in time. The studies conclude that patients no longer visit medical facilities, or visit them too late, because they fear an infection with SARS-CoV-2, resulting in a healthcare access barrier [33-36]. This picture not only emerges for acute cases. There is evidence that patients also used preventive and elective care less [37].

We assume that these results can be applied to our analysis, and that this could be a reason why waiting times were shorter overall in 2020 than in 2019. Patients do not keep their appointments or do not request 
appointments due to the risk of infection with SARS$\mathrm{CoV}-2$. Supporting evidence might also be provided by the varying effects of the different medical specializations on waiting time. Compared with the previous year, the waiting times for otorhinolaryngologists decreased the most. In sum, it seems plausible that patients' higher reluctance to schedule appointments caused the physicians to record an increase in free capacities and to be able to schedule appointments more quickly.

Following this reasoning, it could be assumed that the free capacities are directly linked to a faster allocation of appointments. However, the data analysis shows contradictory results, and patients were even less likely to receive an appointment. This means that even if there is demand, it is served less frequently despite higher free capacities. Hence, the reduced probability of receiving an appointment contradicts the faster allocation of appointments. At the time of data collection, the National Association of Statutory Health Insurance Physicians (NASHIP) had not issued any specific instructions regarding the allocation of appointments (status: April 04, 2020) [38]. Thus, the reduction in supply cannot be attributed to policy interventions. We therefore suggest that reduced supply may also be associated with uncertainty, this time on the provider side. Given that physicians did not receive specific policy instructions and were affected by a completely new situation, non-urgent appointments might have been scheduled less frequently.

Overall, the two main effects suggest that uncertainties due to COVID-19 may have arisen on both the supply and the demand side: Patients go to see physicians less often, and physicians make appointments less frequently. This, however, can cause severe problems when non-urgent cases are left untreated and develop into serious health conditions. The potential risk of focusing only on COVID-19 patients and forgetting about non-COVID-19 patients, such as patients with chronic conditions, has already been pointed out in the literature [26-28, 39]. In the long term, this problem could lead to increased morbidity or mortality in addition to that associated with COVID-19 [27]. This conclusion was also reached in a WHO interim report from 2020, which, in addition to the risk of morbidity and mortality, also indicated that reasons for health service disruption could be attributed to both providers and patients [25].

However, further research is needed to examine the causes of the change in waiting times.

Beside that, the economic consequences of untreated (chronic) diseases must be taken into account. In Germany, an outpatient causes mean costs of $€ 475$ per year, whereas an inpatient causes mean costs of $€ 4239$ [40]. Therefore, cases that are not treated in outpatient care and result in hospitalizations can have a high financial impact, which is compounded by severe disease progression and mortality.

However, beyond the two main effects studied, our analysis was able to obtain other results that correspond to the findings in existing literature. We evaluated a mean waiting time for SHI of 26.13 and for PHI of 17.37 in 2019, and of 17.09 for SHI and 11.09 for PHI in 2020. The waiting times found by Lungen et al. [21], Heinrich et al. [22], and Werbeck et al. [23] are quite similar. Compared to their studies, our experimental design differs in that we selected practices in over- and underserved regions, called the same practices, contacted all practices as both SHI and PHI patients, and collected our data in the same time period in 2019 and 2020, respectively, to avoid seasonal influences. Nevertheless, in line with their findings, we have also identified unequal access to healthcare, depending on patients' insurance status. PHI patients receive an appointment significantly faster and more frequently than SHI patients. This effect was also found in studies of inpatient care as well as in studies without an experimental design $[14,15,19,20]$. Despite the exceptional situation caused by COVID-19, the preferential treatment of PHI patients has not changed. Thus, unequal access to healthcare persists.

In contrast to other studies, we included the level of supply in our analysis to examine whether there are other disparities beside patients' insurance status. In this context, we found that patients receive appointments more quickly in overserved regions than in underserved ones. Waiting times decreased in both levels of supply between 2019 and 2020. Nevertheless, the difference between the regions remained stable. This shows that, in addition to insurance status, the regions' level of supply can also constitute a healthcare access barrier. Although we controlled for the weekday and daytime of call in the extended model of the multivariate analysis, all of these results were robust and significant.

Our study has some limitations. One limitation is that only one call was made per insurance status in each year, and that this single call for SHI and PHI patients may not be representative of ordinary practice organization.

Another limitation arises from the fact that the analysis cannot determine a direct effect of COVID-19 on waiting times. To address this issue, consideration was given to the inclusion of COVID-19 incidence in the multivariate analysis. Unfortunately, incidence values are not available in the administrative districts of the practices for the days of calls. Therefore, the overall incidence for the federal state of Bavaria was included on the days of calls. However, the effect of this variable was not statistically different from zero in either model examined. Furthermore, the previously significant effect of year was also no longer statistically different from zero after COVID-19 incidence had been included, and both 
AIC values worsened. The subsequent examination of the VIF value provided strong evidence of multicollinearity. Therefore, COVID-19 incidence was removed from the models. However, the year dummy can simultaneously be considered a dummy variable for COVID-19.

In addition, a reform was introduced in Germany on May 11, 2019 to ensure that patients receive appointments more quickly (Appointment Service and Supply Act (TSVG)) [41]. Thus, a mixed effect could be present. Given that the reform was introduced with the goal of SHI patients receiving an appointment as quickly as PHI patients [41], however, the study results demonstrate that an unequal distribution still remains. Nevertheless, it can be assumed that the enormous magnitude of the COVID-19 pandemic had a strong impact on the practices. Moreover, our analysis represents only a snapshot at the beginning of the first strong outbreak of COVID19 in Germany and the results may not be generalizable. Waiting times and the likelihood of receiving an appointment can constantly change during the course of the COVID-19 pandemic. Yet despite this, and in light of the possibility of vaccination, our implications remain. We are still in a state of emergency, and it is not yet foreseeable when medical care will be able to return to a regular schedule. Furthermore, such drastic events as the COVID-19 pandemic can occur again, and both physicians and patients should be suitably prepared for these circumstances. The results show that even in exceptional situations such as a pandemic, regular care should not be disregarded and constant care should be maintained for patients. Sufficient resources must be available for physicians to provide medical care alongside pandemic care. At the same time, patients must be supported in seeking medical care as needed. Only through continuous care can inferior health outcomes be avoided. There is now the chance to learn from such observations for the future, to be able to mitigate medical as well as economic risks in the best possible way.

\section{Conclusions}

The statistical analysis of the data collected in our experiment has practical relevance, as it shows that, in addition to the health risk emerging from the COVID19 pandemic, regular patient care is also impaired due to the current situation. Although the waiting times for most medical specializations have decreased, the likelihood of receiving an appointment at all has also decreased. Patient uncertainty due to the fear of a potential infection with SARS-CoV-2 could be the cause of free capacities in practices. If appointments are not kept, there is a long-term risk of worsening health status and thus health outcomes. Beside medical risks, this could also have health economic consequences. Although policy decisions are currently concerned with the COVID-19 pandemic, regular care must not be ignored. It has to be ensured that physicians can treat patients safely in their practices. In addition, encouraging patients to continue to seek medical care and arrange appointments should be of interest to public health. To this end, it is particularly important to moderate patients' fears and uncertainties. This should be ensured by both policymakers and by the healthcare providers themselves. Only if the supply and demand side manage to normalize care, can long-term negative consequences be avoided.

\section{Abbreviations \\ AIC: Akaike information criterion; BASHIP: Bavarian Association of Statutory Health Insurance Physicians; COVID-19: Coronavirus disease 2019; \\ ED: Emergency departments; LMEM: Linear mixed effect model; MAR: Missing at random; NASHIP: National Association of Statutory Health Insurance Physicians; OECD: Organisation for Economic Co-operation and De- velopment; PHI: Private health insurance; SARS-CoV-2: Severe acute respiratory syndrome coronavirus 2; SHI: Statutory health insurance; TSVG: Appointment Service and Supply Act; WHO: World Health Organization}

\section{Acknowledgements}

Not applicable.

\section{Authors' contributions}

JM and CG designed the study. JM collected the data, conducted the analysis, interpreted the data and drafted the manuscript. CG provided guidance on interpretation of the data und gave critical feedback on the manuscript. All authors contributed to the critical revision of the manuscript and approved the final version to be published.

\section{Authors' information}

Not applicable.

\section{Funding}

The research did not receive funding from an external body. Open Access funding enabled and organized by Projekt DEAL.

\section{Availability of data and materials}

The datasets used and analyzed in this study are available from the corresponding author on reasonable request.

\section{Declarations}

Ethics approval and consent to participate Not applicable.

\section{Consent for publication}

Not applicable.

\section{Competing interests}

The authors declare that they have no competing interests.

Received: 28 April 2021 Accepted: 28 September 2021

Published online: 11 October 2021

\section{References}

1. OECD. Waiting times for health services: next in line. Paris: OECD Publishing; 2020. https://doi.org/10.1787/242e3c8c-en.

2. Laudicella M, Siciliani L, Cookson R. Waiting times and socioeconomic status: evidence from England. Soc Sci Med. 2012;74(9):1331-41. https://doi. org/10.1016/j.socscimed.2011.12.049.

3. Sharma A, Siciliani L, Harris A. Waiting times and socioeconomic status: does sample selection matter? Econ Model. 2013;33:659-67. https://doi.org/10.1 016/j.econmod.2013.05.009. 
4. Reichert A, Jacobs R. The impact of waiting time on patient outcomes: evidence from early intervention in psychosis services in England. Health Econ. 2018;27(11):1772-87. https://doi.org/10.1002/hec.3800.

5. Prentice JC, Pizer SD. Delayed access to health care and mortality. Health Serv Res. 2007;42(2):644-62. https://doi.org/10.1111/j.1475-6773.2 006.00626.x

6. Prentice JC, Pizer SD. Waiting times and hospitalizations for ambulatory care sensitive conditions. Health Services and Outcomes Research Methodology, 2008:8(1):1-18. https://doi.org/10.1007/s10742-007-0024-5.

7. Siciliani L, Verzulli R. Waiting times and socioeconomic status among elderly Europeans: evidence from SHARE. Health Econ. 2009;18(11):1295-306. https://doi.org/10.1002/hec.1429.

8. Johar M, Jones G, Keane MP, Savage E, Stavrunova O. Discrimination in a universal health system: explaining socioeconomic waiting time gaps. J Health Econ. 2013;32(1):181-94. https:/doi.org/10.1016/j.jhealeco.2012.09.004.

9. Moscelli G, Siciliani L, Gutacker N, Cookson R. Socioeconomic inequality of access to healthcare: does choice explain the gradient? J Health Econ. 2018; 57:290-314. https://doi.org/10.1016/j.jhealeco.2017.06.005.

10. Monstad K, Engesaeter LB, Espehaug B. Waiting time and socioeconomic status-an individual-level analysis. Health Econ. 2014;23(4):446-61. https:// doi.org/10.1002/hec.2924

11. Olah ME, Gaisano G, Hwang SW. The effect of socioeconomic status on access to primary care: an audit study. Can Med Assoc J. 2013;185(6):E263-9. https://doi.org/10.1503/cmaj.121383.

12. Angerer $\mathrm{S}$, Waibel $\mathrm{C}$, Stummer $\mathrm{H}$. Discrimination in health care: a field experiment on the impact of patients' socioeconomic status on access to care. American Journal of Health Economics. 2019;5(4):407-27. https://doi. org/10.1162/ajhe_a_00124.

13. Asplin BR, Rhodes KV, Levy H, Lurie N, Crain AL, Carlin BP, et al. Insurance status and access to urgent ambulatory care follow-up appointments. JAMA. 2005;294(10):1248-54. https://doi.org/10.1001/jama.294.10.1248.

14. Kuchinke BA, Sauerland D, Wübker A. The influence of insurance status on waiting times in German acute care hospitals: an empirical analysis of new data. Int J Equity Health. 2009;8(1):44. https://doi.org/10.1186/1475-9276-8-44.

15. Roll K, Stargardt T, Schreyögg J. Effect of type of insurance and income on waiting time for outpatient care. Geneva Papers Risk Insur Issues Pract. 2012; 37(4):609-32. https://doi.org/10.1057/gpp.2012.6.

16. Lee $\mathrm{S}$, Gross SE, Pfaff H, Dresen A. Differences in perceived waiting time by health insurance type in the inpatient sector: an analysis of patients with breast Cancer in Germany. INQUIRY: The Journal of Health Care Organization, Provision, and Financing. 2019;56:004695801987589. https:// doi.org/10.1177/0046958019875897.

17. GKV-Spitzenverband. Kennzahlen der gesetzlichen Krankenversicherung. 2021. https://www.gkv-spitzenverband.de/media/grafiken/gkv_kennzahlen/ kennzahlen_gkv_2021_q2/20210901_GKV_Kennzahlen_Booklet_Q2-2021_3 00dpi_barrierefrei.pdf. Accessed 1 Sep 2021.

18. Federal Ministry of Health. The German healthcare system - Strong. Reliable. Proven. 2020. https://www.bundesgesundheitsministerium.de/fileadmin/Da teien/5_Publikationen/Gesundheit/Broschueren/200629_BMG_Das_ deutsche_Gesundheitssystem_EN.pdf. Accessed 8 Jul 2021.

19. Sundmacher $L$, Kopetsch $T$. Waiting times in the ambulatory sector - the case of chronically ill patients. Int J Equity Health. 2013;12(1):77. https://doi. org/10.1186/1475-9276-12-77.

20. Schwierz C, Wübker A, Wübker A, Kuchinke BA. Discrimination in waiting times by insurance type and financial soundness of German acute care hospitals. Eur J Health Econ. 2011;12(5):405-16. https://doi.org/10.1007/s101 98-010-0254-2

21. Lungen M, Stollenwerk B, Messner P, Lauterbach KW, Gerber A. Waiting times for elective treatments according to insurance status: a randomized empirical study in Germany. Int J Equity Health. 2008;7(1):1. https://doi.org/1 0.1186/1475-9276-7-1.

22. Heinrich N, Wübker A, Wuckel C. Waiting times for outpatient treatment in Germany: new experimental evidence from primary data. Jahrbücher für Nationalökonomie und Statistik. 2018;238(5):375-94. https://doi.org/10.1515/ jbnst-2018-0025

23. Werbeck A, Wübker A, Ziebarth NR. Cream Skimming by Health Care Providers and Inequality in Health Care Access: Evidence from a Randomized Field Experiment. IZA Discussion Paper No 13100. 2020.

24. WHO Regional Office for Europe. Coronavirus disease (COVID-19) pandemic. 2020. https://www.euro.who.int/en/health-topics/health-emergencies/ coronavirus-covid-19/novel-coronavirus-2019-ncov. Accessed 10 Jul 2020.
25. World Health Organization. Pulse survey on continuity of essential health services during the COVID-19 pandemic: interim report, 27 August 2020. World Health Organization; 2020. https://apps.who.int/iris/handle/10665/334048.

26. Rosenbaum $\mathrm{L}$. The untold toll — the Pandemic's effects on patients without Covid-19. N Engl J Med. 2020;382(24):2368-71. https://doi.org/10.1 056/NEJMms2009984.

27. Mauro V, Lorenzo M, Paolo C, Sergio H. Treat all COVID 19-positive patients, but do not forget those negative with chronic diseases. Intern Emerg Med. 2020;15(5):787-90. https://doi.org/10.1007/s11739-020-02395-z.

28. Deutsches Ärzteblatt. Rückkehr zur Regelversorgung: Chronische Krankheiten machen keine Coronapause. 2020. https://www.aerzteblatt.de/a rchiv/214065/Rueckkehr-zur-Regelversorgung-Chronische-Krankheiten-ma chen-keine-Coronapause. Accessed 11 Feb 2021.

29. Social Code - Book V - Statutory Health Insurance. 70:1. 1988.

30. de Rosa S, Spaccarotella C, Basso C, Calabrò MP, Curcio A, Filardi PP, et al. Reduction of hospitalizations for myocardial infarction in Italy in the COVID19 era. Eur Heart J. 2020;41(22):2083-8. https://doi.org/10.1093/eurheartj/ ehaa409.

31. Jain N, Berkenbush M, Feldman DC, Eskin B, Allegra JR. Effect of COVID19 on prehospital pronouncements and ED visits for stroke and myocardial infarction. Am J Emerg Med. 2021;43:46-9. https://doi.org/10.1016/j.ajem.2 021.01.024.

32. Garcia S, Albaghdadi MS, Meraj PM, Schmidt C, Garberich R, Jaffer FA, et al. Reduction in ST-segment elevation cardiac catheterization laboratory activations in the United States during COVID-19 pandemic. J Am Coll Cardiol. 2020;75(22):2871-2. https://doi.org/10.1016/j.jacc.2020.04.011.

33. Odone A, Delmonte D, Gaetti G, Signorelli C. Doubled mortality rate during the COVID-19 pandemic in Italy: quantifying what is not captured by surveillance. Public Health. 2021;190:108-15. https://doi.org/10.1016/j.puhe.2 020.11 .016

34. Cosentino N, Assanelli E, Merlino L, Mazza M, Bartorelli AL, Marenzi G. An inhospital pathway for acute coronary syndrome patients during the COVID19 outbreak: initial experience under real-world suboptimal conditions. Can J Cardiol. 2020;36(6):961-4. https://doi.org/10.1016/j.cjca.2020.04.011.

35. Hautz WE, Sauter TC, Exadakytlos AK, Krummrey G, Schauber S, Mller M. Barriers to seeking emergency care during the COVID-19 pandemic may lead to higher morbidity and mortality - a retrospective study from a Swiss university hospital. Swiss Med Weekly. 2020;150:w20331.

36. Gutovitz S, Pangia J, Finer A, Rymer K, Johnson D. Emergency department utilization and patient outcomes during the COVID-19 pandemic in America. The Journal of Emergency Medicine. 2021;60(6):798-806. https:// doi.org/10.1016/j.jemermed.2021.01.002

37. Whaley CM, Pera MF, Cantor J, Chang J, Velasco J, Hagg HK, et al. Changes in health services use among commercially insured US populations during the COVID-19 pandemic. JAMA Netw Open. 2020;3(11):e2024984. https:// doi.org/10.1001/jamanetworkopen.2020.24984.

38. Kassenärztliche Bundesvereinigung. Coronavirus SARS-CoV-2: Kurzüberblick Sonderregelungen. 2020. https://www.kbv.de/media/sp/Coronavirus_ Sonderregelungen_Uebersicht.pdf. Accessed 4 Apr 2020.

39. Kendzerska T, Zhu DT, Gershon AS, Edwards JD, Peixoto C, Robillard R, et al. The effects of the health system response to the COVID-19 pandemic on chronic disease management: a narrative review. Risk Manage Healthc Policy. 2021;14:575-84. https://doi.org/10.2147/RMHP.S293471.

40. Kassenärztliche Bundesvereinigung. Zahlen. 2017. https://www.kbv.de/html/ zahlen.php. Accessed 11 Mar 2021.

41. Bundesministerium für Gesundheit. Terminservice- und Versorgungsgesetz TSVG. 2019. https://www.bundesgesundheitsministerium.de/terminserviceund-versorgungsgesetz.html. Accessed 11 Feb 2021.

\section{Publisher's Note}

Springer Nature remains neutral with regard to jurisdictional claims in published maps and institutional affiliations. 